\title{
A dengue no Rio de Janeiro: repensando a participação popular em saúde
}

\author{
Dengue in Rio de Janeiro: \\ rethinking popular participation in health
}

Rosely Magalhães de Oliveira 1

\footnotetext{
1 Departamento de Endemias Samuel Pessoa, Escola Nacional de Saúde Pública, Fundação Oswaldo Cruz. Rua Leopoldo Bulhões 1480, Rio de Janeiro, $R J$ 21041-210, Brasil.
}

\begin{abstract}
This paper discusses popular participation in health from the point of view of an experience in dengue epidemic control in the late 1980s and early 1990s in the city of Rio de Janeiro. It refers specifically to a social movement called "Se Liga Leopoldina", combining professionals (from health services and public schools) and members of popular organizations from the suburban neighborhoods served by the Leopoldina railway. The paper reviews the ideas motivating actions undertaken by the movement, principally the role of popular organizations in the control of endemics. It calls attention to the danger of preconceived notions when analyzing participation by members of popular organizations in the social movement. The author also calls attention to the fact that social scientists researching social movements should focus on being part of a wider social network of conviviality rather than seeing their role as educating members of the popular organization. Such networks should seek to strengthen and expand social support for the endemic control process.
\end{abstract}

Key words Consumer Participation; Community Participation; Health Education; Collective Diseases; Dengue

Resumo O artigo apresenta uma discussão sobre a participação popular em saúde, a partir de uma experiência vivida durante a epidemia de dengue no município do Rio do Janeiro. Referese, especificamente, ao movimento "Se Liga Leopoldina", que congregou profissionais de saúde (academia e serviços) e membros de organizações populares da região dos subúrbios da Leopoldina. Busca rever as idéias que nortearam as ações do movimento, principlamente no que se refere à participação popular no controle de endemias. Atenta-se para a necessidade de se refutar os (pre)conceitos que envolvem as análises sobre as ações dos sujeitos que integram os movimentos sociais. Identifica-se que a investigação científica na sua relação com os movimentos populares, antes de se colocar como formadora desses movimentos, pode e deve se colocar como integrante de uma ampla rede de convivência, buscando, antes de tudo, o fortalecimento e ampliação das redes sociais de apoio no controle dos processos endêmico-epidêmicos.

Palavras-chave Participação Comunitária; Educação em Saúde; Doenças Coletivas; Dengue 


\section{Introdução}

O presente artigo tem como preocupação central discutir algumas questões relacionadas à participação popular e ao controle de endemias. Seu objetivo não é analisar os números de casos e óbitos das doenças ou questões em torno dos seus determinantes biológicos. Pretendemos, apenas, levantar algumas questões em torno do papel da investigação científica na sua relação com as organizações populares no que se refere ao controle de endemias.

Apresentamos um relato de experiência, a partir de nossa inserção junto a um grupo de pesquisadores do Centro de Estudos e Pesquisas da Leopoldina (Cepel)e da Escola Nacional de Saúde Pública - Fundação Oswaldo Cruz (Ensp - Fiocruz), que busca aprofundar discussões sobre condições de vida e saúde e estreitar a relação entre a investigação científica e as experiências dos grupos populares organizados no município do Rio de Janeiro, mais especificamente na região dos subúrbios da Leopoldina.

Nosso ponto de partida é o relato de uma experiência de mobilização social - movimento denominado "Se Liga Leopoldina" - em torno da epidemia de dengue ocorrida entre os anos de 1986 e 1991 na cidade do Rio de Janeiro. Para tanto, estaremos entendendo o conceito de epidemia para além dos números em que ela se inscreve. A epidemia é tratada como um fenômeno dinâmico, constituído politicamente - tanto quanto cientificamente - nas lutas que perpassam as doenças físicas. Portanto, o contexto e o significado da epidemia são definidos ativamente, tanto pelas suas vítimas como por outros sujeitos a ela relacionados (Stark, 1977).

Em seguida discutimos as principais questões que norteiam o trabalho do grupo de pesquisa, buscando refletir sobre os limites da chamada "capacitação técnica" dos movimentos populares organizados.

Não pretendemos apresentar uma síntese dos resultados dos estudos desenvolvidos por esses grupos, mas, antes de tudo, dividir a experiência de busca de compreensão do cotidiano de amplas camadas da população, apontando os limites e as potencialidades do relacionamento entre as atividades de pesquisa e as organizações populares da sociedade civil.

\section{A emergência da epidemia de dengue: informações que não se cruzam}

As epidemias de dengue ressurgidas no Brasil a partir dos anos 80 apresentam-se, entre as doenças transmitidas por vetores urbanos, co- mo marcadores das condições de receptividade às doenças produzidas por nosso modelo de organização social, representando, de certo modo, o papel ocupado pelas meningites na década de 70. Introduzida a partir de países vizinhos, depois de desaparecer do Brasil desde a década de 20, a dengue ressurgiu sem que o sistema de vigilância epidemiológica fosse capaz de detectá-la e de impedir sua difusão (Sabroza et al., 1992).

No Estado do Rio de Janeiro, em 1986, após cerca de 60 anos sem que nenhum caso da doença fosse notificado, a dengue ressurge primeiramente nos municípios do Grande Rio, configurando uma epidemia que notificou cerca de 90 mil casos no biênio 86/87, todos do sorotipo 1 (FNS, 1997).

No município do Rio de Janeiro, a epidemia teve seu início em abril de 1986 e encerrou o ano com um total de 12.480 notificações. Em 1987, a Secretaria Municipal de Saúde do Rio de Janeiro (SMS/RJ) registrou 37.215 casos. Durante os anos 1988/89, os casos registrados apontavam para um baixo nível de transmissão da doença. Foram notificados, no município, 247 casos em 1988 e 436 em 1989 (Medronho, 1995).

Fatores ligados à dinâmica populacional do vetor da doença, à imunidade da população e, ainda, às mudanças de prioridade em relação às medidas de controle, contribuíram para uma grande instabilidade dos indicadores da dengue no município (Sabroza et al., 1995).

Nos anos 90/91, a epidemia recrudesceu, chegando a totalizar 105 mil casos no Estado. No município os casos notificados atingiram 10.965 em 1990 e 51.695 em 1991. Do total de casos de 1990, 4058 ocorreram em dezembro. No ano de 1991, somente no mês de janeiro, foram notificados 19.979 casos de dengue.

Tanto no Estado como no município do Rio de Janeiro um evento novo ocorreu: além da circulação do sorotipo I, também foram registrados casos do sorotipo II - a dengue hemorrágica. No período 1990/1991 foram notificados no Estado e no município, respectivamente, 1316 e 639 casos de dengue hemorrágica.

$\mathrm{O}$ aumento do número de casos da doença e o surgimento da dengue hemorrágica a partir de 1990 parece não ter sensibilizado as autoridades sanitárias. No inicio de 1991, o Secretário de Saúde do Estado e do Município recusavam-se a reconhecer o recrudescimento da epidemia: "A Secretária Estadual de Saúde, Maria Manoela Alves dos Santos, se esquivou ontem de admitir que o Grande Rio enfrenta uma epidemia de dengue hemorrágica. apesar dos 105 casos registrados, todos em dezembro, e do 
aumento das internações de pacientes com suspeita da doença, na semana passada" (O Globo, 1991).

"O Secretário Municipal de Saúde, Pedro Valente, negou que os casos de dengue registrados na primeira quinzena de janeiro tenham duplicado. Afirmou que os 4163 casos desse periodo foram apenas notificados, mas não confirmados. Valente acredita que os sintomas da dengue do tipo I podem ter sido confundidos com os de enxaqueca e de rubéola" (O Dia, 1991).

As informações sobre o recrudescimento da epidemia e o surgimento de casos de dengue hemorrágica aliados à ausência de medidas efetivas de controle implicou a mobilização de profissionais de saúde (serviços e academia) e da opinião pública. Assim, não foi por iniciativa das autoridades sanitárias que as informações vieram a público. Na época, um pesquisador da Fundação Oswaldo Cruz, em entrevista à imprensa, chamou atenção para o fato de que quem primeiro "levantou a lebre" foi a população: "Se pegarmos o material publicado pela imprensa na época, veremos que quem diagnosticou [a] epidemia foi o movimento comunitário da Baixada [Fluminense] e não a vigilância epidemiológica do Estado. Quem mostrou que as crianças não estavam indo à aula, que o pessoal não conseguia sair para trabalhar, que havia uma doença estranha, foi a população. Não foi o sistema de vigilância epidemiológica, como ocorre em qualquer país onde ela é estruturada. E isso é lamentável" - Entrevista do pesquisador Rivaldo Venâncio do Departamento de Medicina Tropical da Fiocruz e ex-Coordenador da Campanha Estadual Contra a Dengue (O Globo, 1990).

Assim, no início, as informações sobre a iminente epidemia - que já deveriam estar amplamente difundidas nos meios de comunicação de massa - circulavam de forma restrita entre as de redes formais e informais de relações entre profissionais e usuários dos serviços que estavam atentos para o aumento de casos de dengue hemorrágica com a chegada do verão e começaram a se articular. Essa rede alcançava os fóruns locais de discussões sobre saúde (grupos de apoio, oficinas, comissões locais de saúde).

\section{A emergência da mobilização social: o movimento "Se Liga Leopoldina" e seus desdobramentos}

No período de eclosão da epidemia de dengue, estavam em pleno funcionamento na Ensp Fiocruz as Oficinas de Educação Popular, Saú- de e Participação Popular, que haviam sido criadas em 1989 como desdobramento dos trabalhos da equipe do Núcleo de Educação, Saúde e Cidadania na Escola Nacional de Saúde Pública (Nesc/Ensp). Esse núcleo, durante seis anos (1986-1992), elaborou e executou projetos de pesquisa na região dos subúrbios da Leopoldina, onde também está instalada a sede da Fundação Oswaldo Cruz. Em articulação com os serviços locais de saúde e organizações populares, o funcionamento desse Núcleo de Pesquisa também inspirou a criação do Cepel (Centro de Estudos e Pesquisas da Leopoldina), entidade que, desde então, tem desenvolvido atividades de assessoria às organizações populares da região.

As Oficinas foram criadas com base nas solicitações de assessoria por parte de organizações populares da região da Leopoldina. Eram compostas por profissionais de saúde (academia e serviços), profissionais de educação e de representantes de organizações populares. Inicialmente, as Oficinas foram constituídas para a capacitação dos representantes populares, mas, com o tempo, percebeu-se que os profissionais também demandavam informações sobre as experiências de vida da população. As Oficinas passaram, então, a se constituir num espaço de capacitação mútua e simultânea dos profissionais e representantes da população (Valla et al., 1993).

Na região da Penha, onde se desenvolvia o projeto de pesquisa, somente em um dia (29 de novembro de 1990) foram notificados $100 \mathrm{ca}-$ sos da doença, sendo confirmado pelo menos um caso de dengue hemorrágica na comunidade do Parque Proletário da Penha.

Não tardou para que a epidemia de dengue entrasse na pauta de discussões das Oficinas. Na penúltima Oficina, em outubro de 1990, já próximo à chegada do verão, ao mesmo tempo que a população vivia a experiência da doença, a informação da iminência de uma epidemia de dengue hemorrágica chegava à Oficina por parte de profissionais dos serviços locais de saúde. As discussões giraram em torno do fato de as autoridades sanitárias não divulgarem as informações sobre os casos de dengue hemorrágica, apesar de o vírus do tipo II já ter sido isolado desde abril de 1990. Uma das razões apontadas para explicar o fato de as autoridades sanitárias não reconhecerem, publicamente, a existência da epidemia eram as possíveis conseqüências para o turismo: as informações sobre a epidemia de dengue hemorrágica poderia afugentar os turistas esperados na cidade naquele verão, trazendo prejuízos econômicos para o município. 
Os relatos sobre as ameaças da emergente epidemia de dengue também passaram a fazer parte da pauta de reuniões da Comissão Executiva de Saúde da Área de Planejamento 3.1 (CEAP) e do Grupo Executivo Local (GEL), que eram espaços institucionalizados de caráter consultivo, reconhecidos pela Secretaria Municipal de Saúde, onde se discutiam os problemas de saúde nas regiões da Leopoldina e Ilha do Governador. Participavam dessas reuniões profissionais de saúde e representantes da sociedade civil organizada.

Da articulação entre os espaços das Oficinas e das reuniões do CEAP e do GEL, surgiu a proposta de se criar um movimento que tivesse o caráter de defesa civil popular, o "Se Liga Leopoldina”. Duas questões básicas levavam à avaliação de que o debate sobre a epidemia deveria tomar as ruas: a) o contexto que se apresentava era o de emergência, no qual o sistema de saúde não era capaz de fazer frente à doença de maneira eficaz; logo a população precisava tomar medidas de defesa contra a proliferação dos mosquitos; 2) as informações divulgadas pelo governo mascaravam a realidade, pois referiam-se apenas ao aconselhamento de medidas individuais para evitar a doença. Era o momento de desconstruir as informações que “culpabilizavam a vítima” (Valla, 1993) e colocar à tona a relação entre condições de vida e saúde e seus determinantes. Assim, o eixo das discussões deveria ser deslocado para a distribuição da verba pública.

Acreditava-se que o movimento pudesse munir a população com informações sobre a relação entre suas condições de vida e situação de saúde da população e levar a uma qualificação das reivindicações sociais. A questão central que se colocava era a seguinte: “O Estado vem se eximindo de suas responsabilidades de provedor de serviços básicos de consumo coletivo, o que tem favorecido o aparecimento de diversas enfermidades que estão se tornando endêmicas. O contexto apresentado atualmente é o da população, tendo cada vez mais que assumir uma defesa civil da vida, quando deveria atuar em caráter de participação social efetiva na definição de políticas sociais, ou seja, apontar os serviços prioritários, sua distribuição, qualidade e adequação à realidade da população. O movimento popular não tinha, na sua relação com os órgãos públicos, as informações necessárias sobre os serviços básicos prestados (ou que deveriam ser prestados), informações estas que poderiam subsidiar suas lutas pela aquisição desses serviços em qualidade e de acordo com a sua realidade. No confronto com o Estado torna-se, então, necessária a apropria- ção de informações pela população (sua "capacitação técnica") para que possa estabelecer uma nova relação com o Estado na luta pela garantia de serviços públicos de qualidade" (Valla et al., 1993: 28).

O que estava por trás dessa questão era o desejo de que a discussão sobre a relação entre as condições de vida e saúde pudesse levar as organizações populares a pressionar, de forma mais qualificada, os governos, para que estes aplicassem recursos em áreas prioritárias. $\mathrm{O}$ momento da epidemia de dengue tornava-se estratégico para colocar publicamente as conseqüências, para a saúde, da distribuição desigual da verba pública.

O “Se Liga Leopoldina” programou e realizou diversos eventos na região, culminando com dois atos públicos que foram preparados em reuniões semanais com representantes da sociedade civil organizada. Foram produzidos e distribuídos à população diversos folhetos explicativos que enfatizavam a relação entre condições de vida e saúde. Como principal instrumento de socialização do conhecimento foi produzida a cartilha "Se Liga Gente, a Dengue Está Aí”.

De um lado, o material informativo produzido e divulgado pelos órgãos centralizados dos serviços de saúde limitava-se ao aconselhamento de medidas de comportamento individual adequado à prevenção da doença (tais como acabar com a água parada, não acumular lixo no peri-domicilio). De outro, as informações sistematizadas e divulgadas no nível local, numa aliança entre técnicos e organizações populares, enfatizavam a relação entre as condições de vida e saúde, com especial destaque para as áreas de favelas, onde a disponibilidade de recursos sanitários é precária e muitas vezes inexistente. O problema central que emergiu dessa discussão foi exatamente o fato de as áreas de favelas não contarem com serviço regular de abastecimento de água e de coleta de lixo. Em razão desta precariedade, os moradores eram obrigados a armazenar água em caixas, barris e latões, e a depositar lixo em terrenos baldios, locais ideais para a proliferação de mosquitos. Buscava-se denunciar a “culpabilização da vítima”, presente nas mensagens e reportagens veiculadas pelos meios de comunicação em que "a falta de consciência da população" e a "não ajuda ao combate dos focos" eram a constante. Procurava-se, portanto, ampliar a discussão sobre a doença, levantando questões não apontadas pelos governos e que requeriam uma atuação mais permanente: colocava-se a premência do saneamento básico nas áreas de favelas, espe- 
cialmente abastecimento de água e limpeza pública.

Não demorou muito para que a adesão de profissionais dos serviços ao movimento repercutisse nos órgãos centrais de decisão. A direção das instituições de saúde colocaram em pauta o limite entre ser profissional e ser cidadão. Dois profissionais que se aliaram ao movimento foram proibidos por suas instituições de dar entrevista sobre a epidemia de dengue em curso, o que levou um deles a falar à imprensa no dia de realização de atos públicos, como cidadão participante. As proibições não se restringiram ao setor saúde e à relação com a imprensa: uma profissional da área de educação, professora de uma escola da região, foi proibida de participar das manifestações.

$\mathrm{Na}$ avaliação dos organizadores as reuniões preparatórias e os eventos constituíram-se "em momentos muito importantes de troca, pois os moradores participavam ativamente na elaboração do ato, discutindo, opinando, informando. Deste intercâmbio produziu-se um novo conhecimento, resultante das informações técnicas mais as experiências de vida da população" (Valla et al., 1993:24).

A experiência trazida pelo movimento "Se Liga Leopoldina" teve como um de seus desdobramentos uma luta mais ampliada pelo direito à informação. A avaliação de que os orgãos governamentais geralmente dificultam o acesso às informações oficiais e que isso "dificulta o trabalho de técnicos no desenvolvimento das ações de saúde e não permite a visão dos grupos populares sobre os determinantes de suas condições de vida e trabalho" (Valla et al., 1993:31) levou à discussão da proposta de criação de um Sistema de Informações de Nível Local (Sinal).

A criação do SINAL teve como premissa principal a sistematização e difusão de informações valendo-se de uma rede informal de relações na qual participantes atuam na condição de cidadãos, produzindo de maneira sistemática dados sobre as condições de vida da população na Leopoldina e que permitem subsidiar a luta do movimento popular por serviços de consumo coletivo de qualidade necessários à sobrevivência da população. Criou-se, então, uma metodologia de organização de um sistema de informação, cujo objetivo é a "construção coletiva do conhecimento". Por meio dessa metodologia, a produção da informação se dá pela contribuição do conhecimento dos profissionais de saúde e educação e representantes das camadas populares e a sua divulgação é dirigida aos serviços e entidades populares, entre outras. Trata-se, portanto, de um processo de produção de informação resultante da relação/interação entre o conhecimento científico e o saber popular.

Constituindo-se uma nova abordagem de construção de sistema de informação, a proposta de construção do Sinal foi assumida e colocada em execução pelo Centro de Estudos e Pesquisas da Leopoldina (Cepel). Fazem parte desse sistema: a) o Centro de Documentação sobre as Condições de Vida na Leopoldina (Cedvida), onde são armazenados dados e informações sobre condições de vida na região da Leopoldina e sobre políticas públicas na cidade do Rio, provenientes tanto de matérias publicadas na imprensa, quanto de relatórios de pesquisa, entrevistas, documentos de diversas entidades populares e de instituições públicas, fotografias, etc.; b) o jornal "Se Liga no Sinal”: veículo impresso de divulgação, bimensal, de informações sobre as condições de vida na região; e c) cursos e seminários ministrados pela equipe do Cepel, espaço onde circulam, simultaneamente, informações sobre a conjuntura política e sobre como a população está "se virando".

Este sistema também é constantemente alimentado por informações produzidas com base nas pesquisas realizadas pelo Cepel, pela Ensp/Fiocruz e por outros grupos que produzem informações sobre a Leopoldina.

Passados quase 7 anos do pico da epidemia de dengue e da mobilização popular em torno da epidemia na região, os serviços de saúde, incapazes de eliminar os criadouros do vetor, conseguiram, às custas de muitas toneladas de inseticidas por aspersão e na água de utilização doméstica, apenas diminuir a intensidade da transmissão da dengue. À medida que diminuiu a intensidade de transmissão da doença, e essa ficou limitada às áreas periféricas, onde as ações de controle são menores, diminuiu, também, a repercussão da doença na imprensa e a prioridade de seu controle (Sabroza et al., 1992).

Em relatório sobre a evolução da dengue no Rio de Janeiro, a Coordenadoria Regional da FNS no Estado do Rio de Janeiro avalia que a dengue no Rio de Janeiro, no período 86/96, apresentou picos epidêmicos sazonais com intervalos de 2 a 3, anos sendo que a partir de 1998 haveria a "possibilidade de um novo surto com conseqüencias imprevisíveis, dependendo dos sorotipos circulantes" e, lembrando ainda do risco potencial da reurbanização da febre amarela (FNS, 1997).

A transmissão da doença encontra-se restrita a determinados grupos sociais e o discurso dominante dos programas oficiais ainda remete ao indivíduo as questões do controle da 
doença. O discurso que "culpabiliza a vítima” retomou toda sua força, principalmente por intermédio dos meios de comunicação. Uma das mais expressivas campanhas e que representa uma síntese da disseminação de preconceitos e, também, a negação do problema da dengue como um problema coletivo é a seguinte: "se você não se cuidar a dengue vai te pegar”.

Avaliamos que, apesar de as ações de controle da dengue serem bastante limitadas, os serviços de saúde conseguiram reconstituir sua legitimidade quanto à vigilância da doença e a rede social de apoio ao movimento popular, tão ampliada no período da epidemia, também retornou aos seus níveis endêmicos.

\section{Repensando a participação popular no controle de endemias}

Passado o pico da epidemia de dengue e com a doença voltando aos seus níveis endêmicos, um grupo de pesquisadores do Cepel e da Ensp ainda dá continuidade aos estudos sobre condições de vida e saúde na região. Muitas experiências foram trocadas e novas reflexões emergiram. Muitas das certezas daquele momento agora são dúvidas. Uma contribuição que certamente ficou foi o aprofundamento sobre as percepções e formas de agir dos distintos sujeitos que compõem os movimentos sociais. Assim, sentimos-nos obrigados a repensar a questão da participação popular no controle de endemias.

As ações que nortearam o trabalho do grupo de pesquisa tinham como ponto de partida a identificação de "carências" de informação entre os participantes do movimento. Tanto as organizações populares como os profissionais teriam uma "carência", principalmente no que se refere às dificuldades de acesso às informações técnicas e sobre as experiências de vida. Acreditava-se que o novo conhecimento construído na relação entre os dois grupos pudesse suprir essa "carência", e levaria o movimento social a avançar nas suas lutas pela conquista de um patamar elevado de condições de reprodução da força do trabalho e do exercício da cidadania. Desta forma, a participação popular "efetiva" se daria quando se pretendesse ou se conseguisse modificar o orçamento estatal de modo a conquistar a provisão de serviços básicos necessários.

Essa participação popular "efetiva” deveria ser colocada em contraposição a outras formas de participação apregoadas pelos programas governamentais, principalmente quando estes perdem o controle dos agravos que ameaçam a “população como um todo”. Neste sentido, a forma ideal de participação social seria aquela em que os atores teriam a capacidade de apontar as áreas em que julgam necessária a intervenção estatal. Tendo esse princípio como ponto de partida, o papel principal que caberia à investigação científica seria devolver à população interessada os dados sistematizados na forma de subsídio técnico (Valla \& Stotz, 1991; Valla, 1993).

A insistência em trabalhar junto aos movimentos populares e as constantes reflexões e trocas com parceiros de outros grupos de pesquisa nos levou a um questionamento sobre a questão da participação popular: será que o estabelecimento e a busca de um padrão ideal de participação comunitária "efetiva” não significaria uma ação normalizadora, da mesma forma que as outras formas de participação social apregoadas pelos programas oficiais de controle de endemias? À medida que o ideal de participação social "efetiva" também foi construído fora do mundo de significados e de experiências dos grupos populares, não seria ele, também, uma prescrição?

Com a continuidade da pesquisa e com o trabalho contínuo de assessoria aos grupos populares organizados da Leopoldina, observamos que, apesar da aparente contradição, o que ocorre no interior dos movimentos populares é a convivência entre diversas formas de participação, cada uma delas com um potencial de mudança, dependendo da significação e dos usos que os grupos populares fazem delas.

Entendemos que a epidemia de dengue colocou às claras a insuficiência dos investimentos públicos necessários para a superação das condições de receptividade e de vulnerabilidade que propiciam o aparecimento e a manutenção das doenças transmissíveis entre as camadas populares da população. Não podemos desconhecer que hoje, na conjuntura neoliberal, mais do que nunca, faz-se necessário pensar mecanismos de pressão para a inversão das prioridades dos investimentos. No entanto, a análise das possibilidades de transformação não pode ficar restrita apenas aos espaços institucionalizados, onde se dão os embates políticos mais diretos. Temos de reconhecer que, para grande parte dos integrantes dos movimentos populares, as possibilidades de ação podem ser encontradas em outros espaços e tempos da vida social. Existe uma variedade de ações comunitárias, mediadas por suas histórias e culturas que, embora não sejam tão visíveis, representam verdadeiras invenções do ponto de vista da transformação da realidade local. Ao lado das práticas políticas de pressão 
direta junto ao Estado podemos encontrar outras práticas comunitárias que, do ponto de vista dos grupos populares, são iniciativas que podem transformar a realidade.

Victor Valla, um dos coordenadores do movimento “Se Liga Leopoldina”, tem buscado repensar os eixos teóricos e metodológicos utilizados ao longo de vários anos de pesquisa e de assessoria popular e vem apontando para a necessidade de uma mudança na forma de olhar para as classes populares, principalmente no que se refere à nossa compreensão sobre suas maneiras de conhecer e agir no mundo (Valla, 1996, 1997).

Em pesquisa sobre a qualidade dos serviços de água e esgoto na região da Leopoldina, observamos que a luta pela água na região sempre se desenvolveu por aproximações sucessivas. Em muitas comunidades e favelas, principalmente as mais antigas, a conquista da ligação à rede pública de abastecimento de água foi resultado da luta simultânea que envolvia ações locais de defesa da vida (construção de bicas, ligações clandestinas), aliança com diversos agentes de mediação (Igreja, políticos, profissionais) e, quando possível, pressão direta no aparelho de Estado. De acordo com as interpretações que os grupos populares possam fazer com relação às possíveis alianças e ao seu potencial de resolução, a pressão sobre o Estado pode ser maior ou menor. Em muitos casos a pressão sobre o Estado sequer estava programada. Um bom exemplo é o das ligações clandestinas de água. Quando os moradores das favelas fazem os "gatos" na rede pública de água ou de luz, a única intenção é ter água em seu domicílio, porém essa ação traz problemas para o sistema de abastecimento como um todo, pois as casas com ligações oficiais também passam a sofrer com a falta de água. Desta forma o Estado se vê obrigado a buscar soluções, mesmo que provisórias, para as comunidades onde o "gato" é dominante (Oliveira, 1993, 1996).

Em recente pesquisa (Cunha \& Oliveira, 1997) sobre favelas na Região da Penha (XI Região Administrativa) constatamos que grande parte das obras de infra-estrutura foram conquistadas por meio de uma luta que se desenvolve, simultaneamente, pelas iniciativas comunitárias e de pressão junto ao Estado.

Nas favelas, a tarefa de gerenciar e controlar seus problemas coletivos é assumida pela população em função da percepção de ineficiência do Estado que está aí estruturado, que durante anos adia continuamente a realização de obras prometidas por políticos e outros agentes externos. As formas de agir dos sujei- tos, para alcançar seus objetivos (a arte de fazer), variam enormemente, de acordo com a importância relativa atribuída aos diferentes bens, materiais e simbólicos que reivindicam e que dependem de uma variedade de significados que orientam suas ações (Sader, 1988; Certeau, 1994).

Quando "movimentamos nosso binóculo" em direção às experiências de vida dos diversos sujeitos que compõem o movimento popular, podemos visualizar diversas significações para uma mesma realidade, tempos diferentes se realizando (Cunha, 1996). Atentamos que ao invés de olharmos somente para as suas carências devemos olhar, também, para as suas potencialidades. Talvez assim, no lugar de sujeitos "apáticos", possamos encontrar sujeitos portadores de história e cultura comunitárias de invenção e reinvenção permanentes. Estas (re)invenções, todavia, não podem ser vistas independentemente dos movimentos de reprodução. Pois como analisa Martins (1996:22) "fazer história não está apenas no ato intencional de criar o novo e destruir o velho. Uma História assim é, no fundo, uma História sem tensões, sem vida, falsa história. No vivido a práxis é contraditória. Ela reproduz as relações sociais. Mas, Lefebvre observa, não há reprodução das relações sociais sem uma certa produção de relações, 'não há repetição sem inovação'." (destaque nosso).

No caso da participação da academia no processo epidêmico da dengue, o foco da atenção concentrou-se na "capacitação técnica" e na "construção compartilhada do conhecimento", partindo-se do princípio de que o acréscimo de informação e/ou a produção de um novo conhecimento, que faltava para os diversos sujeitos, promoveria a transformação da realidade. Mas, se as ações dos sujeitos, são conduzidas muito mais por suas interpretações sobre as possibilidades de conquista do que pelo acréscimo de informação, perguntamos no que a "capacitação técnica” estaria contribuindo para "qualificar o movimento"?

Avaliamos que o potencial transformador da relação entre investigação científica e grupos populares não se encontra no fato de se produzirem novas informações, mas principalmente no fato de permitir uma maior dinamização do uso das informações que circulam informalmente. Portanto, o ponto de partida não pode ser a "capacitação técnica”, mas sim o estabelecimento de uma "rede social de apoio", uma rede de convivência em que a razão e a paixão, conflito e solidariedade, caminham lado a lado e a capacitação técnica é mais uma de suas conseqüências. 
Na verdade, a "construção coletiva do conhecimento", muito mais do que determinante do fortalecimento dos sujeitos, é uma conseqüência da estruturação e fortalecimento de uma "rede social de apoio". Rede essa que possibilita a ampliação e o fortalecimento dos sujeitos, à medida que potencializa o uso das distintas informações. A ação transformadora dos sujeitos se dá então, muito mais, pela ampliação e fortalecimento das relações do que necessariamente pela construção de uma nova informação. Quando os sujeitos, mesmo informados, não se sentem apoiados, procuram outros espaços onde estão colocadas outras oportunidades de apoio e invenção. À medida que os sujeitos se sentem apoiados, sentem-se mais seguros para se lançar no mundo, para arriscar, para falar e escrever sua própria história. Não se trata de "despertar" ou "sensibilizar” a população, como pretendem os programas oficiais de educação em saúde e muitos outros. Trata-se de valorizar aquilo que os sujeitos têm de melhor, sua história, seu tempo a sua capacidade de criação.

Durante esses anos de estudo, apesar da grande proximidade com movimento popular, ainda estávamos acostumados com as grandes generalizações e pretendendo "explicar" a dinâmica dos movimentos sociais com base nas condições objetivas que os envolvem e desconhecendo justamente aquilo que singulariza os movimentos: "a particularidade de seus imaginários" (Sader, 1988:42).

\section{Movimentos que pulsam simultaneamente: algumas lições sobre processos endêmico- epidêmicos e a mobilização popular}

Como vimos, com a eclosão da epidemia de dengue no município do Rio de Janeiro, a legitimidade das instituições governamentais de saúde ficou ameaçada, principalmente pela sua fragilidade exposta nos meios de comunicação. Esta situação proporcionou uma ampla aliança, antes restrita, entre técnicos e população. Naquele momento, os profissionais de saúde, fossem eles técnicos dos serviços ou das universidades, e representantes de organizações populares, colocaram-se como agentes de um amplo movimento social pela saúde. Emergiu, junto com a epidemia, a insatisfação da população com a seletividade na distribuição da verba pública e a insatisfação dos profissionais com os programas de governo a que estão hierarquicamente subordinados. A crise de legitimidade, momentaneamente trazida pela eclosão da epidemia, trouxe para os sujeitos integrantes do movimento popular outras possibilidades de ação, até então estancadas.

Assim, como nos ensina Stark (1977), podemos entender que uma epidemia é uma fenômeno dinâmico, política e cientificamente constituído nas lutas que se disseminam junto com a doença. As epidemias, portanto, são "eventos sociais" não só pelo fato de serem, cada vez mais, gerados por fatores comportamentais, sociais e ambientais, mas também, porque esses fatores são, eles próprios, cada vez mais, simultaneamente, reflexos e condicionantes das lutas pelo controle do produto social.

Nos períodos endêmicos, quando a transmissão da doença restringe-se a áreas de maior vulnerabilidade e parece que a doença não ameaça “toda a população", as alianças entre técnicos e população são mais restritas e/ou menos visíveis, e os movimentos populares se sentem mais fragilizados para o enfrentamento público direto com o Estado. Quando os números da doença indicam endemicidade e a transmissão está restrita às áreas de maior vulnerabilidade e os moradores dessas áreas identificam que a opinião pública não lhes dá mais atenção, o campo de possibilidades para a ação fica mais restrito. É necessário buscar força em outros espaços/tempos. Assim, verificamos que nos períodos endêmicos as potencialidades de transformação são deslocadas, predominantemente, para o lugar de onde nunca deixaram de estar: o cotidiano dos sujeitos e da comunidade. Neste espaço, o caminho é mais estreito, mas nem por isso menos dinâmico e inventivo. Suas ações são mais de ocasião, são menos planejadas, e nem por isso são só repetições. Nos períodos endêmicos, ao contrário dos epidêmicos, a potencialidade dos movimentos populares encontra-se, predominante, nos movimentos do homem comum: num caminho que é percorrido e vivido a cada momento. Pois, " $a$ despeito das aparências, são os homens comuns, pobres e "lentos", os mais velozes na descoberta de uma nova solidariedade na cidade" (Santos, 1993: 7).

Buscar compreender esse caminho é buscar a compreensão dos processos endêmicoepidêmicos para além do valor fascinante dos números de casos e óbitos das doenças. É buscar compreendê-lo (o processo) "como uma instância de sentido, que é significativa para sujeitos de cultura" (Samaja, 1995:8). Nesta perspectiva, nossa preocupação volta-se não apenas para a manifestação dos casos de doenças, mas, principalmente, para os contextos de vida, aos ambientes e aos mecanismos pelos quais se reproduzem e são renegociados cons- 
tantemente os processos endêmico-epidêmicos. O interesse volta-se menos para as causas das doenças e mais para os processos e os efeitos desencadeadores dos problemas de saúde.

\section{Considerações finais}

Fundamentados em um relato de experiência, buscamos compartilhar algumas de nossas reflexões acerca da "construção coletiva do conhecimento" e do fortalecimento e ampliação das "redes sociais de apoio" no controle dos processos endêmico-epidêmicos. Atentamos para a necessidade de nos desarmarmos de (pre)conceitos quando buscamos analisar a ação dos sujeitos que integram os movimentos sociais, apontando que a compreensão dos limites e possibilidades de ação desses sujeitos só pode ser feita no contexto de relações em que se encontram inseridos.

Acreditamos que a investigação científica, mais do que oferecer subsídios técnicos para qualificar a ação das organizações comunitárias, deve se colocar como integrante de uma ampla rede de convivência, em que circulam razão e emoção, técnicas e afetos. Talvez, desta forma, possamos verificar que por trás da aparente "apatia" dos grupos populares existe um mundo extremamente dinâmico que deve ser valorizado, principalmente no seu potencial inventivo. Talvez possamos enxergar, muito mais do que as carências, as verdadeiras potencialidades desses sujeitos na transformação da sociedade. Quem sabe, assim, façamos emergir discursos menos carregados de (pre)conceitos e possamos contribuir para a dissolução dos "discursos competentes" cujo conteúdo e forma já foram autorizados segundo seus cânones e competência (Chauí, 1980).

Ressaltamos que, em tempos atuais, a interpretação dos grupos populares de que o Estado que está aí estruturado não quer ceder às pressões, tem levado, cada vez mais, a busca de soluções através de outros caminhos. Caminhos estes para os quais devemos estar atentos, à medida que podem estar apontando para outras potencialidades para além daquelas que aprendemos a prescrever como corretas.

Por fim, gostaríamos de levantar algumas questões que consideramos importantes para a reflexão, principalmente para aqueles que se dedicam às atividades de educação, informação e participação social em saúde: a) será que são as informações que potencializam a ação ou é o convívio entre distintos sujeitos que fornece as possibilidades de ação, através da ampliação e fortalecimento das redes sociais de apoio? b) é possível haver adesão dos sujeitos a uma proposta de transformação, somente porque estes ficaram "melhor/mais informados" ou é necessário que estes sujeitos também se sintam valorizados/apoiados? c) diante de uma perspectiva de retirada do Estado das políticas sociais, e do conseqüente aumento da vulnerabilidade dos grupos populares aos problemas sociais, será possível pensar ações de participação social em saúde apenas a partir dos espaços institucionalizados, como os conselhos de saúde?

\section{Referências}

CERTEAU, M., 1994. A Invenção do Cotidiano. Petrópolis: Vozes.

CHAUÍ, M. S., 1980. O discurso competente. In: Cultura e democracia: o discurso competente de outras falas (M. S. Chauí, org.), pp. 3-14, São Paulo: Ed. Moderna.

CUNHA, M. B., 1996. Movimentando o binóculo: das análises que imobilizam às falas que interrogam. Cadernos CEDES, 38:72-83.

CUNHA, M. B. \& OLIVEIRA, R. M., 1997. Relatório Técnico de Pesquisa Construindo Indicadores Sobre as Condições de Vida nos Bairros e Comunidades da Região de Leopoldina. Vol. II. Rio de Janeiro: Cepel/ Elos/Ensp.

O DIA, 1991. Secretário diz que não existe surto de dengue. O Dia, pp. 5, 25 de janeiro. 
FNS (Fundação Nacional de Saúde), 1997. Evolução do Agravo de Dengue no Estado do Rio de Janeiro no Triênio 1995/1997. Rio de Janeiro: Fundação Nacional de Saúde/Coordenação do Rio de Janeiro/Serviço de Epidemiologia. (mimeo.)

O GLOBO, 1990. Rio poderá ter epidemia de dengue hemorrágica. $O$ Globo, p. 22, 16 de dezembro.

O GLOBO, 1991. Manoela não confirma surto. O Globo, p. 11, 06 de janeiro.

MARTINS, J. S., 1996. As temporalidades da história na dialética de Lefebvre. In: Henri Lefebvre e o Retorno à Dialética (J. S. Martins, org.), pp. 13-23, São Paulo: Hucitec.

MEDRONHO, R. A.,1995. Geoprocessamento e Saúde: uma Nova Abordagem do Espaço no Processo Saúde-Doença. Rio de Janeiro: Cict/Nect/Fiocruz.

OLIVEIRA, R. M., 1993. A Distribuição Desigual dos Serviços de Água e Esgoto no Município do Rio de Janeiro: O Caso da Região da Leopoldina. Dissertação de Mestrado, Rio de Janeiro: Escola Nacional de Saúde Pública/Fiocruz.

OLIVEIRA, R. M., 1996.Construindo o conhecimento sobre o saneamento básico nas favelas através das "falas" e informações da população. Cadernos CEDES, 38:62-71.

SABROZA, P. C.; TOLEDO, L. M. \& OSANAI, C. H., 1992. A organização do espaço e os processos endêmicos epidêmicos. In: Saúde, Ambiente e Desenvolvimento (M. C. Leal, P. C. Sabroza, R. H. Rodrigues \& P. M. Buss, orgs.), vol 2, pp. 57-77, Rio de Janeiro: Abrasco/São Paulo: Hucitec.

SABROZA, P. C.; KAWA, H. \& CAMPOS, W. S. Q., 1995. Doenças transmissíveis: ainda um desafio. In: $O s$ Muitos Brasis: Saúde e População na Década de 80
(M. C. S. Minayo, org.), pp. 177-244, São Paulo: Hucitec/Rio de Janeiro:Abrasco.

SADER, E., 1988 Quando Novos Personagens Entraram em Cena: Experiências, Falas e Lutas dos Trabalhadores da Grande São Paulo (1970-80). São Paulo: Paz e Terra.

SAMAJA, J., 1995. Epistemología y epidemiología. III Congresso Brasileiro, II Congresso Ibero-Americano, I Congresso Latinoamericano de Epidemiologia, Resumos. Salvador, Bahia: Abrasco.

SANTOS, M.,1993. Metrópole: a força dos fracos é o seu tempo lento. Ciência \& Ambiente. 7:7-12.

STARK, E., 1977. The epidemic as a social event. International Journal of Health Service, 7:681-705.

VALLA, V. V., 1993. Participação popular e saúde: a questão da capacitação técnica no Brasil. In: Participação Popular, Educação e Saúde: Teoria e Prática (V. V. Valla \& E. N. Stotz, orgs.), pp. 55-86, Rio de Janeiro: Relume-Dumará.

VALLA, V. V., 1996. A crise de interpretação é nossa: procurando compreender a fala das classes subalternas. Educação \& Realidade, 21:177-191.

VALLA, V. V., 1997. Apoio social e saúde: buscando compreender a fala das classes populares. In: $V$ Congresso Brasileiro de Saúde Coletiva e V Congresso Paulista de Saúde Pública. Resumos. Águas de Lindóia, São Paulo: Abrasco.

VALLA, V. V. \& STOTZ, E. N., 1991. Participação Popular e Saúde. Petrópolis: CDDH/Cepel.

VALLA, V. V.; CARVALHO, M. \& ASSIS, M., 1993. Participação Popular e os Serviços de Saúde: o Controle Social como Exercício da Cidadania. Rio de Janeiro: Escola Nacional de Saúde Pública/Fiocruz. 